\title{
80 Aniversario de Escuela Nacional de Salud Pública
}

\author{
80th anniversary of the National School of Public Health
}

\author{
Pastor Castell-Florit Serrate \\ Director, Escuela Nacional de Salud Pública. La Habana, Cuba.
}

Compañero Ministro de Salud Pública

Compañeras y compañeros

Haré referencia de manera resumida, a las principales tareas que ha emprendido la Escuela Nacional de Salud Pública en su última etapa.

La fusión, a inicios de este siglo, de la Facultad de Salud Pública y el Centro Nacional de Perfeccionamiento Médico propició la creación de la actual Escuela Nacional de Salud Pública, la que ha mantenido como premisa durante todos estos años al igual que sus antecesores, trabajar vinculado a los sistemas y servicios de salud por ser estos su verdadera razón de ser. Esta es una institución académica multicéntrica, de alcance nacional, que se encarga de formar y superar a especialistas, docentes y directivos del sistema, realizar investigaciones científicas y ofertar servicios científico-técnicos en el campo de la salud pública, la educación médica y la historia de la medicina, con una plena integración intra e intersectorial y un alto grado de profesionalidad.

Las actividades realizadas en los últimos años han sido de creciente complejidad y magnitud. En la etapa más reciente de trabajo ha resultado una prioridad en el Centro la concepción, gestación y puesta en marcha del sistema de preparación en dirección en salud, en cumplimiento de la función que la institución ejerce como escuela ramal de cuadros del Sistema Nacional de Salud, sustentada en el funcionamiento, a lo largo del país, de los centros provinciales de la Escuela Nacional de Salud Pública.

Por otra parte, la misión dada a la institución por la dirección del Ministerio de Salud Pública, de formar de manera incrementada especialistas, másteres y doctores en el campo de la salud pública y la educación médica, ha requerido un 
importante esfuerzo de todo el colectivo del Centro, así como una intensa preparación científica y metodológica, para constituir un claustro de reconocido prestigio académico y sólida formación político-ideológica y científico-pedagógica.

Este trabajo ha propiciado un fructífero intercambio de nuestros profesores con profesionales del sector tanto en Cuba como en otros países donde cumplen misiones internacionalistas.

Los principales resultados en esta etapa han estado vinculados a la integración y unidad de acción con el Partido Comunista de Cuba, la administración, el sindicato y la Unión de Jóvenes Comunistas, ha sido la fortaleza para el logro de la excelencia institucional. Esto ha contribuido a que nuestro Centro sea colectivo moral y vanguardia nacional del Sindicato Nacional de Trabajadores de la Salud, así como que un número importante de trabajadores posea categoría superior en la emulación socialista.

Hemos sido acreditados como programas de excelencia, en las maestrías de Salud Pública y Psicología de la Salud, y certificadas las de Atención Primaria y de Educación Médica Superior durante los procesos de acreditación establecidos por el Ministerio de Educación Superior. Esto forma parte del patrón de calidad de la educación superior cubana.

Dentro de las actividades docentes el sistema de preparación en dirección en salud ha tenido una constante y progresiva atención, lo que ha conllevado reajustes en su concepción, para mejores resultados en un futuro inmediato.

Ha sido otra tarea permanente el desarrollo sistemático del claustro de la sede central de la Escuela y nos proyectamos igualmente con este objetivo con los centros provinciales.

Un grupo importante de profesores han obtenido reconocimientos o títulos honoríficos. El centro posee 24 profesores consultantes, 3 investigadores de mérito, 2 profesores de mérito y 4 académicos, así como 24 profesores titulares.

La comisión de grados científicos y el programa de doctorado en ciencias de la salud funcionan de manera estable, podemos mostrar un incremento progresivo del número de aspirantes en este programa y la integración de doctores al claustro a tiempo completo que asciende en estos momentos a 27 para el $36 \%$. Se trabaja con igual ímpetu para lograr cifras superiores con los profesores a tiempo parcial.

El desarrollo del programa de doctorado en Venezuela y de otras figuras académicas de postgrado, han mostrado destacada participación lo que ha requerido la presencia de más del $80 \%$ del claustro de la escuela en estas actividades.

La investigación científica para posible toma de decisiones a partir de sus resultados ha estado encaminada a resolver los principales problemas del sector. De hecho el Programa Ramal de Investigaciones en sistemas y servicios de salud se ha perfeccionado sistemáticamente y se han incrementado en número y calidad los proyectos presentados por la institución en convocatorias de programas ramales. El $56 \%$ de los profesores están incorporados a proyectos de investigación, aunque todos los profesores sin excepción investigan en sistemas y servicios de salud, por la necesidad manifiesta de estos procesos en la actividad formativa. 
Referente al Forum de Ciencia y Técnica hemos tenido destacada participación con un número importante de profesores, estudiantes y trabajadores.

El apoyo importante a las revistas de salud pública y educación médica, así como a la serie monográfica de historia de la salud pública, continúan con pasos firmes para mostrar de manera constante los avances científicos en esas esferas. La revista INFODIR (Información para directivos), publicó los primeros números.

La gestión económica de la Escuela se consolida y perfecciona. También se ha implementado gradualmente el sistema de control interno y la resolución 297/03 del Ministerio de Finanzas y Precios. Somos además, una institución con control económico durante cinco años consecutivos. I gualmente, todas las actividades académicas e investigativas desarrolladas por la institución han tenido un adecuado apoyo logístico.

En el área docente fueron identificadas y normalizadas las competencias laborales, de igual forma fueron evaluados y certificados el desempeño del $100 \%$ de los trabajadores no docentes.

Las actividades de la defensa y la preparación para desastres y contingencias han resultado también objeto de atención y en la etapa han sido consolidadas.

Otras actividades destacadas han sido:

- El funcionamiento relevante de las cátedras "J osé Martí" y "Ernesto Che Guevara" como parte del trabajo político ideológico del centro.

- Institución auspiciadora de la Academia de Ciencias de Cuba.

- Institución más destacada en la instancia central de la $31^{\text {ra }}$ edición del concurso Premio Anual de la Salud.

- Reelección de la Escuela en el grupo directivo de la Asociación Latinoamericana de Educación en Salud Pública.

- Elegida como centro Coordinador regional del Campus Virtual de Salud para Centroamérica y el Caribe.

Algunas de las proyecciones de trabajo que nos proponemos son:

- Consolidar la proyección nacional de la Escuela, a través del fortalecimiento y protagonismo de los centros provinciales en la labor de preparación y superación de los directivos del Sistema Nacional de Salud.

- Perfeccionar el proceso formativo de los cuadros y profesionales del sistema a través de doctorados, maestrías y otras figuras académicas de posgrado.

- Perfeccionar el sistema de preparación profesoral, como vía para el logro de la excelencia institucional.

- Perfeccionar e incrementar los proyectos de investigación en correspondencia con los principales problemas de salud pública cubana. 
- Continuar perfeccionando la integración administrativa, política y sindical, con vistas a obtener la condición de Institución de excelencia.

- Acompañar, como elemento integrante del Sistema Nacional de Salud, la consecución de las Proyecciones de la Salud Pública cubana hasta el año 2015, con énfasis especial en sus directrices generales.

Considero que la Escuela Nacional de Salud Pública ha desarrollado un permanente trabajo dirigido hacia el redimensionamiento de su proyección, y se ha trazado una política de desarrollo estratégico que toma en consideración los aciertos de periodos anteriores y asimila las principales tendencias en la enseñanza de la salud pública y la educación médica, teniendo como contexto nuestro sistema económico y social socialista que resiste durante ya casi 50 años las agresiones de todo tipo de la potencia imperialista más poderosa en la historia de la humanidad.

Las dificultades que aún persisten continuarán siendo objeto de especial atención, a partir del reconocimiento de que el capital humano que poseemos es su principal fortaleza.

La institución continuará, en los años venideros, con sus mejores tradiciones históricas, en función de mejorar la salud de nuestro pueblo y consecuente con el pensamiento y la obra de Martí y Fidel.

Finalmente quiero expresar un especial reconocimiento en el día de hoy a las mujeres y los hombres que en estos 80 años de enseñanza de la Salud Pública en Cuba han predicado con su ejemplo y han desbrozado el camino por el cual más de una generación de salubristas han transitado y por el que se aprestan a transitar muchos más. De esta forma, la Escuela Nacional de Salud Pública continuará profundizando su huella histórica como estandarte de la Escuela Cubana de la Salud Pública. 